US Army Corps

of Engineers ${ }_{\circledast}$

Engineer Research and

Development Center

Integrated Climate Assessment for Army Enterprise Planning

\title{
Temperature and Precipitation Projections Model User's Guide
}

Byron M. Garton

July 2019

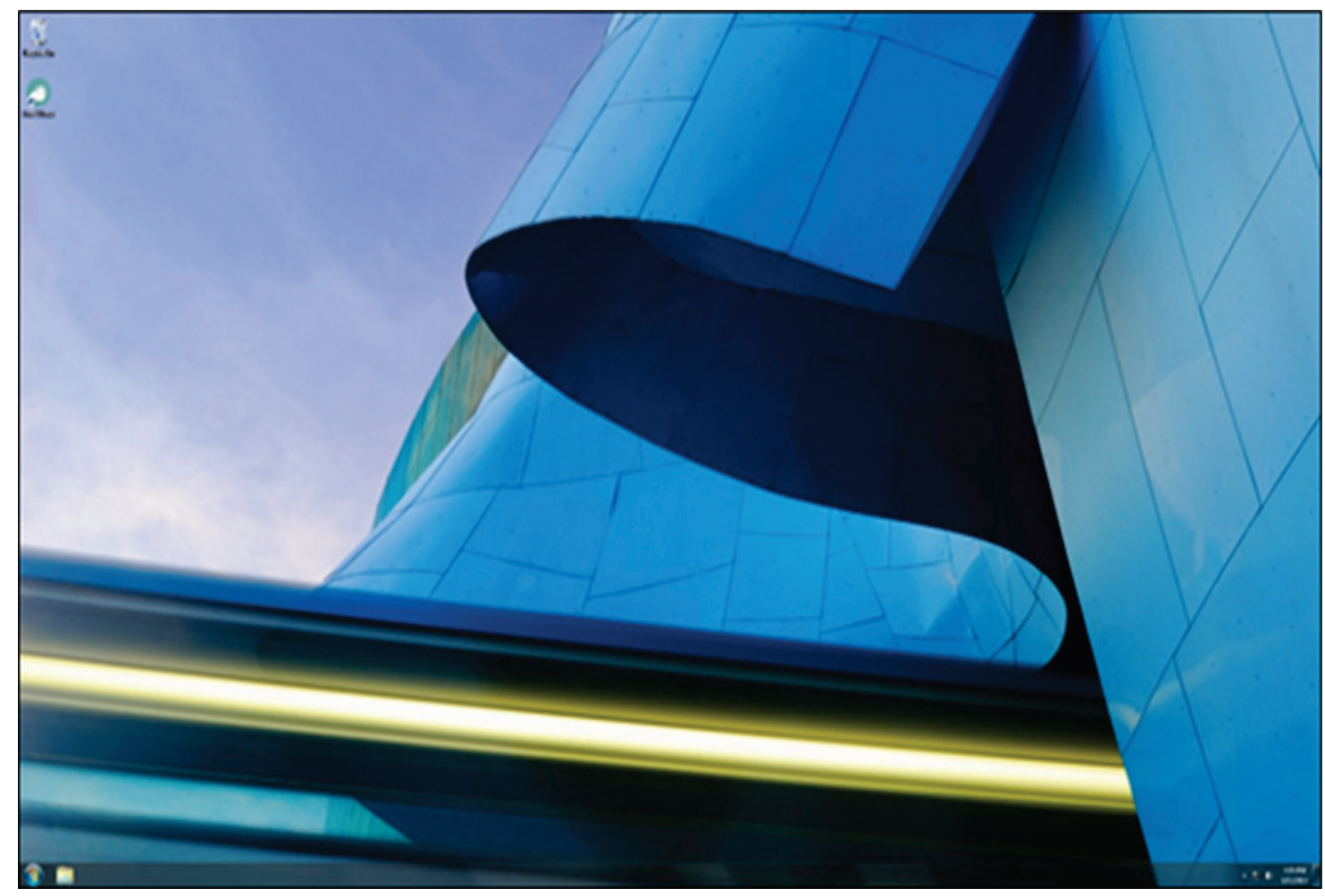


The U.S. Army Engineer Research and Development Center (ERDC) solves the nation's toughest engineering and environmental challenges. ERDC develops innovative solutions in civil and military engineering, geospatial sciences, water resources, and environmental sciences for the Army, the Department of Defense, civilian agencies, and our nation's public good. Find out more at www.erdc.usace.army.mil.

To search for other technical reports published by ERDC, visit the ERDC online library at http://acwc.sdp.sirsi.net/client/default. 


\title{
Temperature and Precipitation Projections Model User's Guide
}

\author{
Byron M. Garton \\ Information Technology Laboratory \\ U.S. Army Engineer Research and Development Center \\ 3909 Halls Ferry Road \\ Vicksburg, MS 39180-6199
}

Final report

Approved for public release; distribution is unlimited.

\author{
Prepared for U.S. Army Corps of Engineers \\ Washington, DC 20314-1000 \\ Under Project 402188 Integrated Climate Assessment for Army Enterprise Planning
}




\section{Abstract}

The potential effects of climate change on temperature and precipitation at Department of Defense (DoD) installations are far ranging, and understanding their impacts is essential to maintaining optimal force stationing and readiness. This model attempts to predict changes in daily and monthly average temperature and precipitation for several scenarios from future climate projections for various DoD installations.

This document describes the process of executing the Temperature and Precipitation Projections Model, as it exists at the time of this publication, within the common computational environment established under the software integration effort of the Integrated Climate Assessment for Army Enterprise Planning work package.

DISCLAIMER: The contents of this report are not to be used for advertising, publication, or promotional purposes. Citation of trade names does not constitute an official endorsement or approval of the use of such commercial products. All product names and trademarks cited are the property of their respective owners. The findings of this report are not to be construed as an official Department of the Army position unless so designated by other authorized documents. 


\section{Contents}

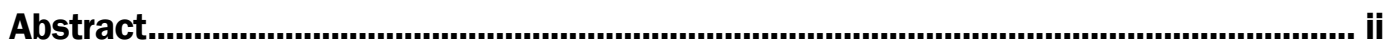

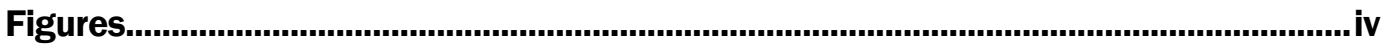

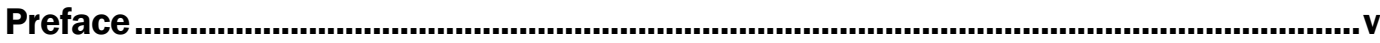

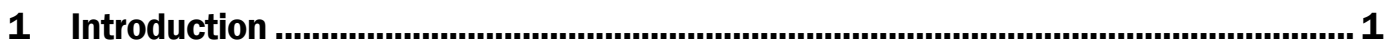

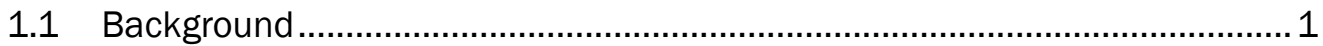

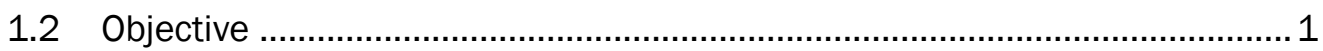

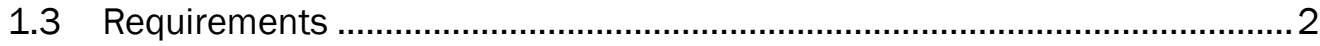

2 Viewing Computed Data.......................................................................................... 3

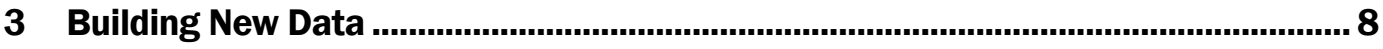

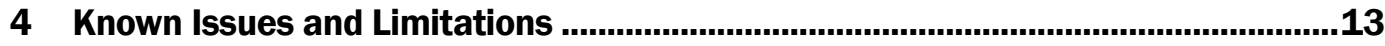

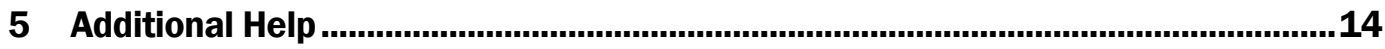

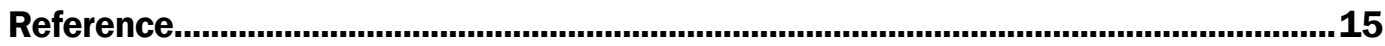

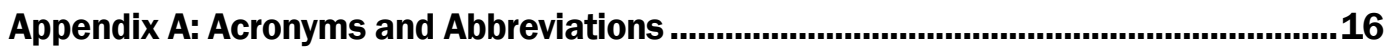

Report Documentation Page 


\section{Figures}

\section{Figures}

Figure 1. Wizard application shortcut............................................................................. 3

Figure 2. Temperature and Precipitation Projections Model icon. ...................................... 4

Figure 3. Temperature and Precipitation Projections Model first screen. ............................ 4

Figure 4. Temperature and Precipitation Projections Model second screen. ...................... 5

Figure 5. Results in the chart viewer window. ................................................................ 6

Figure 6. Chart comparison filter. .................................................................................. 6

Figure 7. Launch R Studio from the third model screen within the Wizard. ......................... 8

Figure 8. R Studio development environment............................................................... 9

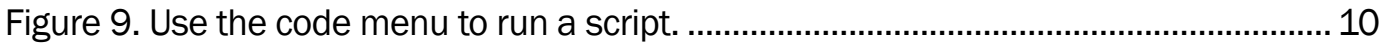

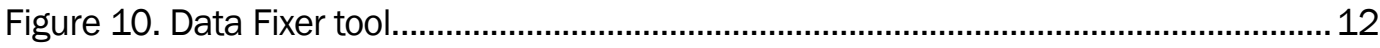




\section{Preface}

This research was conducted for the U.S. Engineer Research and Development Center-Construction Engineering Research Laboratory (ERDC-CERL) under Project 402188, Integrated Climate Assessment for Army Enterprise Planning. The Technical Monitor was Dr. James D. Westervelt of ERDC-CERL.

The work was performed by the Information Technology Laboratory (ITL), Scientific Software Branch (SSB), of the Computational Science and Engineering Division (CSED). At the time of publication, Mr. Timothy W. Dunaway was Chief of the SSB, Dr. Jerrell R. Ballard was Chief of the CSED, and Dr. Robert M. Wallace was the Technical Director. The Deputy Director of ERDC-ITL was Ms. Patti S. Duett, and the Director was Dr. David A. Horner.

COL Ivan P. Beckman was the Commander of ERDC, and Dr. David W. Pittman was the Director. 


\section{Introduction}

\subsection{Background}

The Temperature and Precipitation Projections Model attempts to predict the effects of climate change on temperature and precipitation at various Department of Defense (DoD) installations. Many different methods for modeling climate change have been created and tested over the years. Under the World Climate Research Programme (WCRP), the Working Group on Coupled Modelling (WGCM) established the Coupled Model Intercomparison Project (CMIP) as a standard experimental protocol for studying the output of coupled atmosphere-ocean general circulation models (AOGCMs). The CMIP facilitates assessment of the strengths and weaknesses of climate models which can enhance and focus the development of future models. For example, if the models indicate a wide range of values either regionally or globally, then scientists may be able to determine the cause(s) of this uncertainty. $\mathrm{CMIP}_{5}$ (formally the Coupled Model Intercomparison Project Phase 5) is the most current and extensive of the CMIPs.

\subsection{Objective}

The objectives of $\mathrm{CMIP}_{5}$ are to:

- Evaluate how realistic the models are in simulating the recent past

- Provide projections of future climate change on two time scales, near term (out to about 2035) and long term (out to 2100)

- Understand some of the factors responsible for differences in model projections, including quantifying some key feedbacks such as those involving clouds and the carbon cycle.

The Temperature and Precipitation Projections Model parses CMIP 5 data that is stored in Network Common Data Format (NetCDF) files. NetCDF is a machine-independent data format that is often used for the sharing of array-oriented scientific data such as that produced during the $\mathrm{CMIP}_{5}$ study. Temperature and precipitation data is extracted by the model for a series of DoD installations, and output into the standard comma separated values (CSV) format. The exported values represent daily and monthly temperature and precipitation projections into the future broken into 
10-year increments starting at the year 2020 and going up to the year 2100. Monthly data is further processed into average values for each month within a 10-year epoch and also averages for the entire epoch.

\subsection{Requirements}

Software requirements for the Temperature and Precipitation Projections Model include the R Studio development environment, a basic text editor such as MS Notepad ${ }^{\circledR}$, and MS Excel ${ }^{\circledR}$ version 2013 or higher.

A working knowledge of Microsoft Office products is recommended as well as a basic understanding of editing file paths in a text file and executing $\mathrm{R}$ code within the R Studio environment.

Hardware requirements for this model are substantial. A minimum of nine processor cores (eight required for script) are required to execute the code. Memory minimum requirements are 64 gigabytes (GB) of random access memory (RAM) and 5 terabytes (TB) of hard disk storage space (local or network). 


\section{Viewing Computed Data}

Pre-built dataset viewing is available to end users by accessing the model from within the Wizard application. The Wizard is accessible from the Integrated Climate Assessment for Army Enterprise Planning VM by clicking the shortcut located on the desktop (Figures 1-3).

Figure 1. Wizard application shortcut.

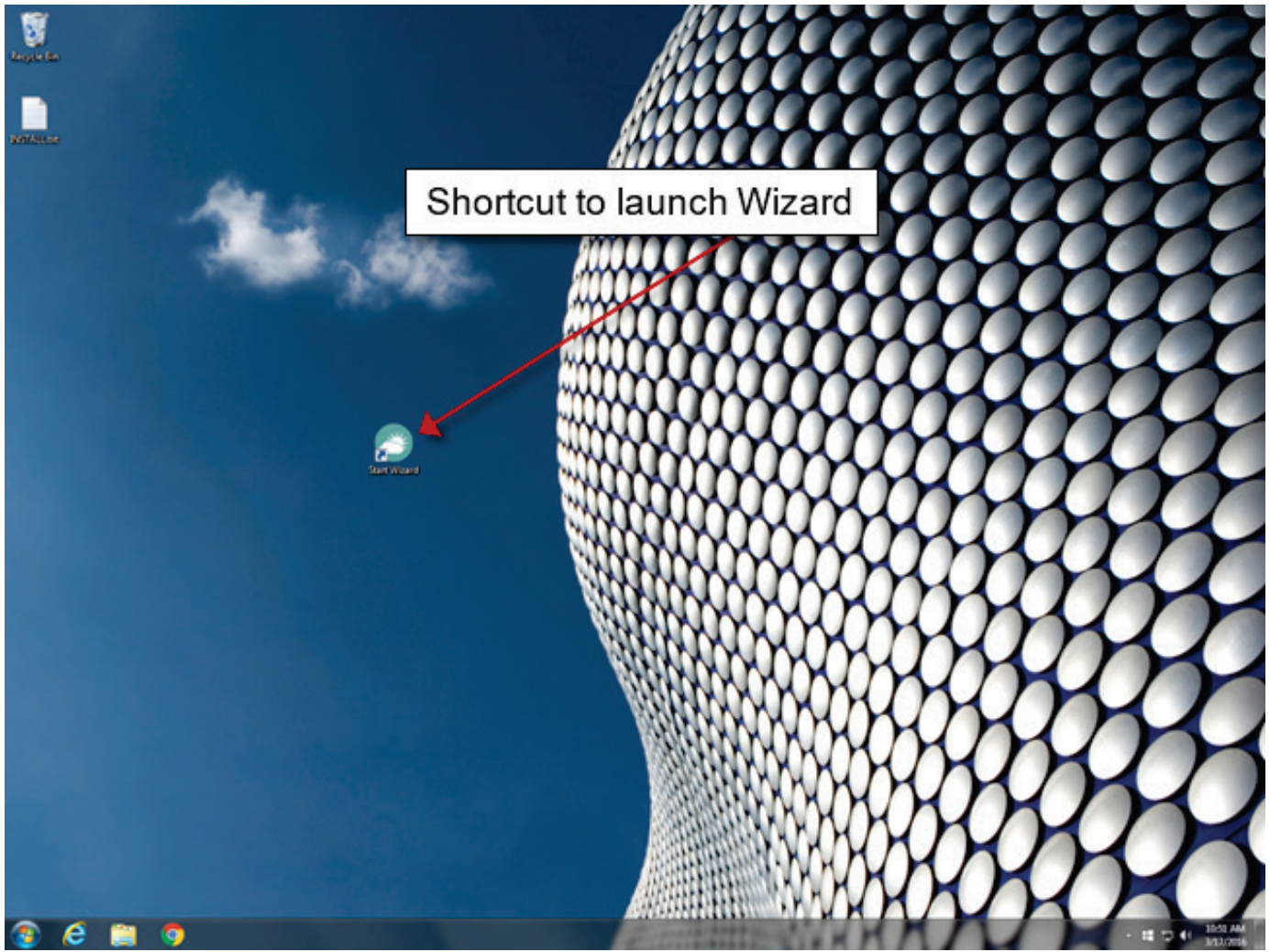


Figure 2. Temperature and Precipitation Projections Model icon.

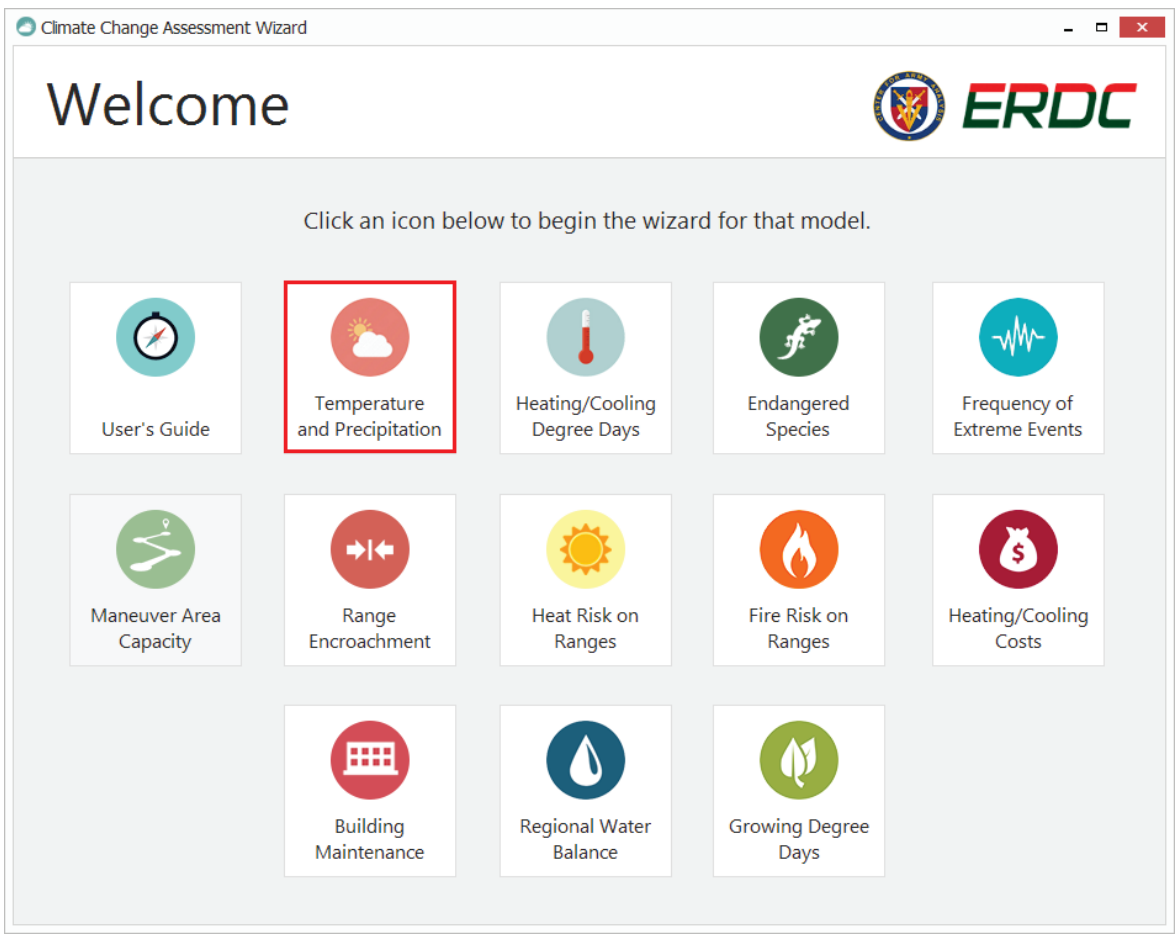

Figure 3. Temperature and Precipitation Projections Model first screen.

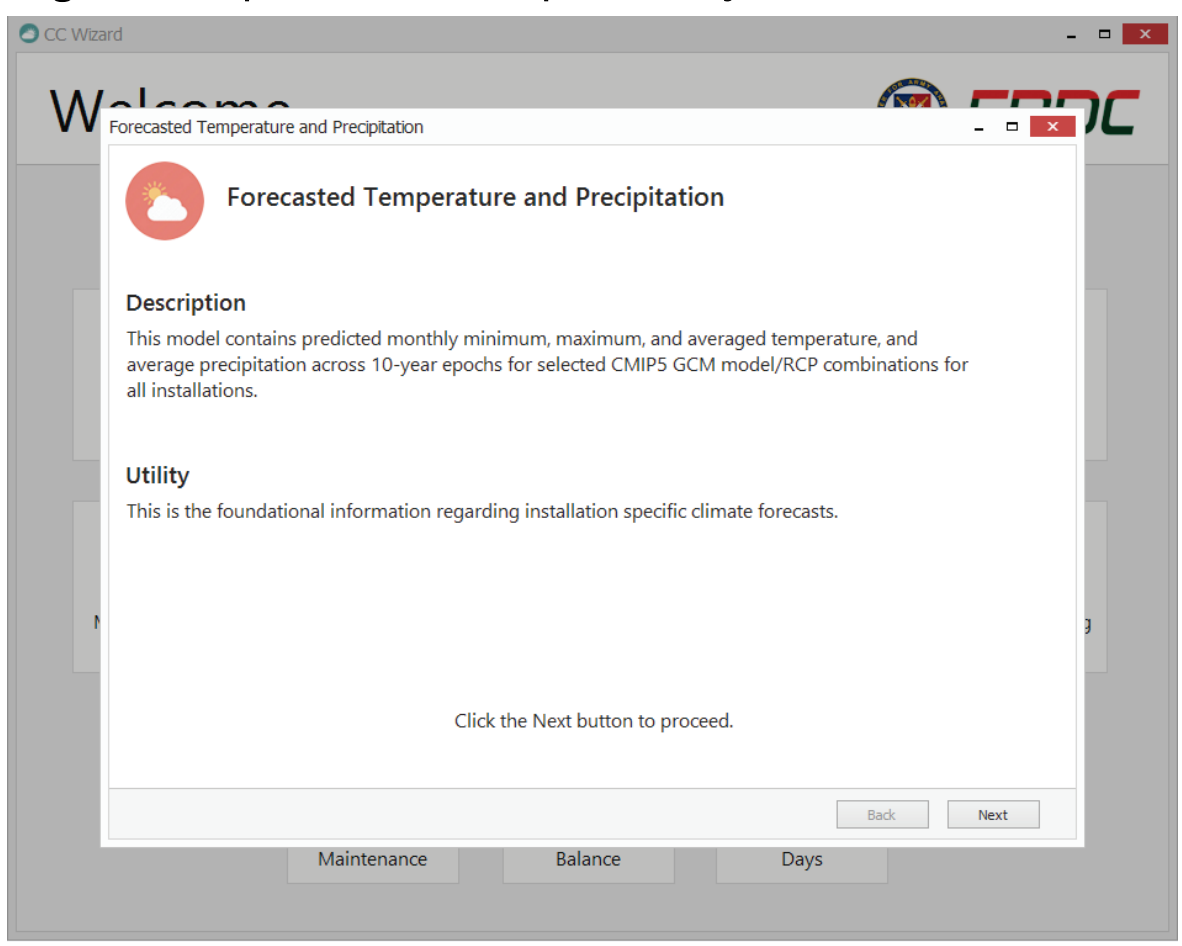

The second screen within the model (Figure 4) allows the end user to view the datasets in graphical or tabular mode. Choose the desired view type from the View drop down combo box. Options within this box are Graphs 
and Tabular. Graphs displays the data as standard line graphs while Tabular displays the data in a table layout within an MS Excel ${ }^{\circledR}$ spreadsheet.

Figure 4. Temperature and Precipitation Projections Model second screen.

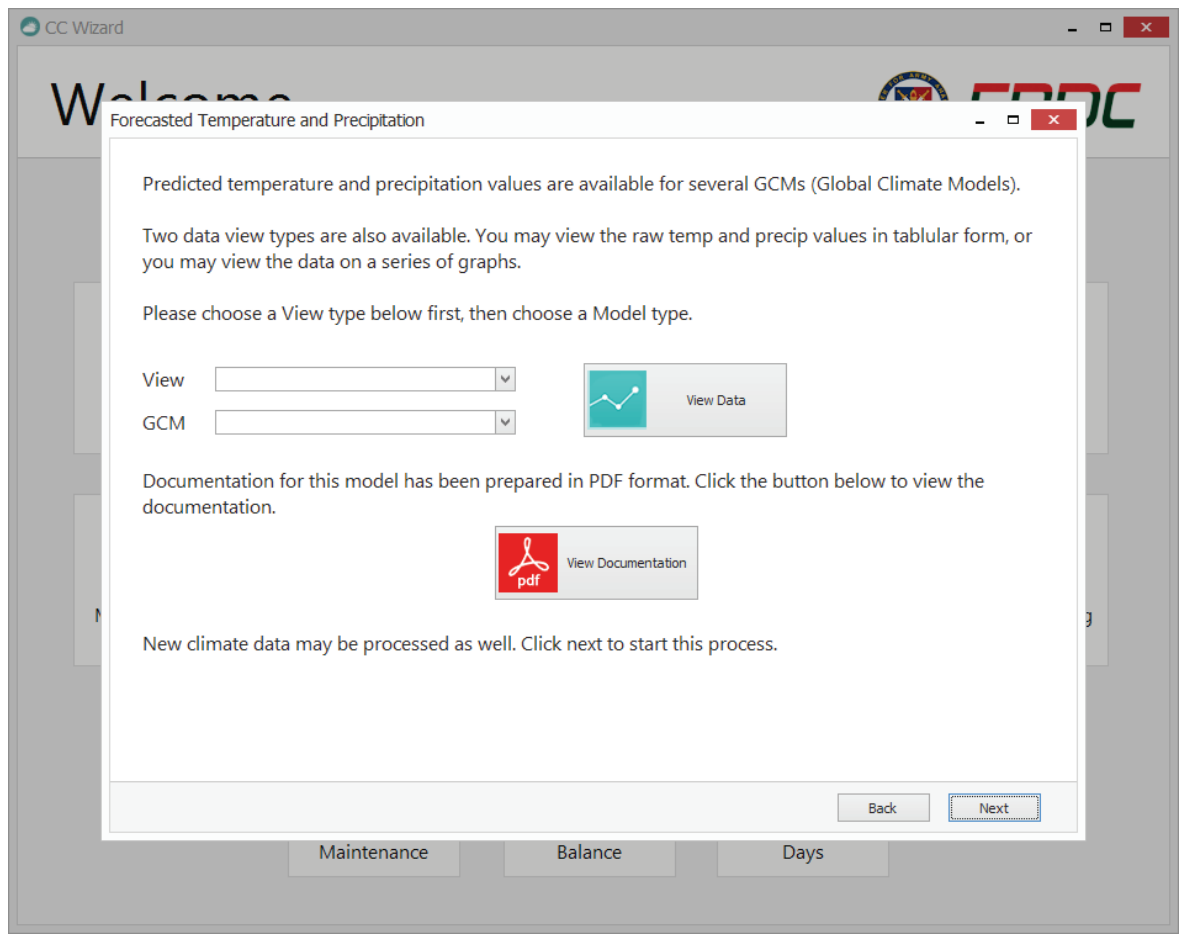

Next, choose a General Circulation Model (GCM) and Representative Concentration Pathway (RCP) type from the drop down combo box to filter only data related to that GCM/RCP (Figure 4). At the time of this publication, there are ten GCMs within the dataset for this model. RCP 2.6, 4.5, and 8.5 were chosen to represent lower bound, middle, and upper bounds for each GCM. Each GCM contains these RCPs, with the exception of CNRM-CM- 5 and GFDL-CM3.

Once both of the choices are made, click the View Data button to launch the chart viewer window (Figure 5). 
Figure 5. Results in the chart viewer window.

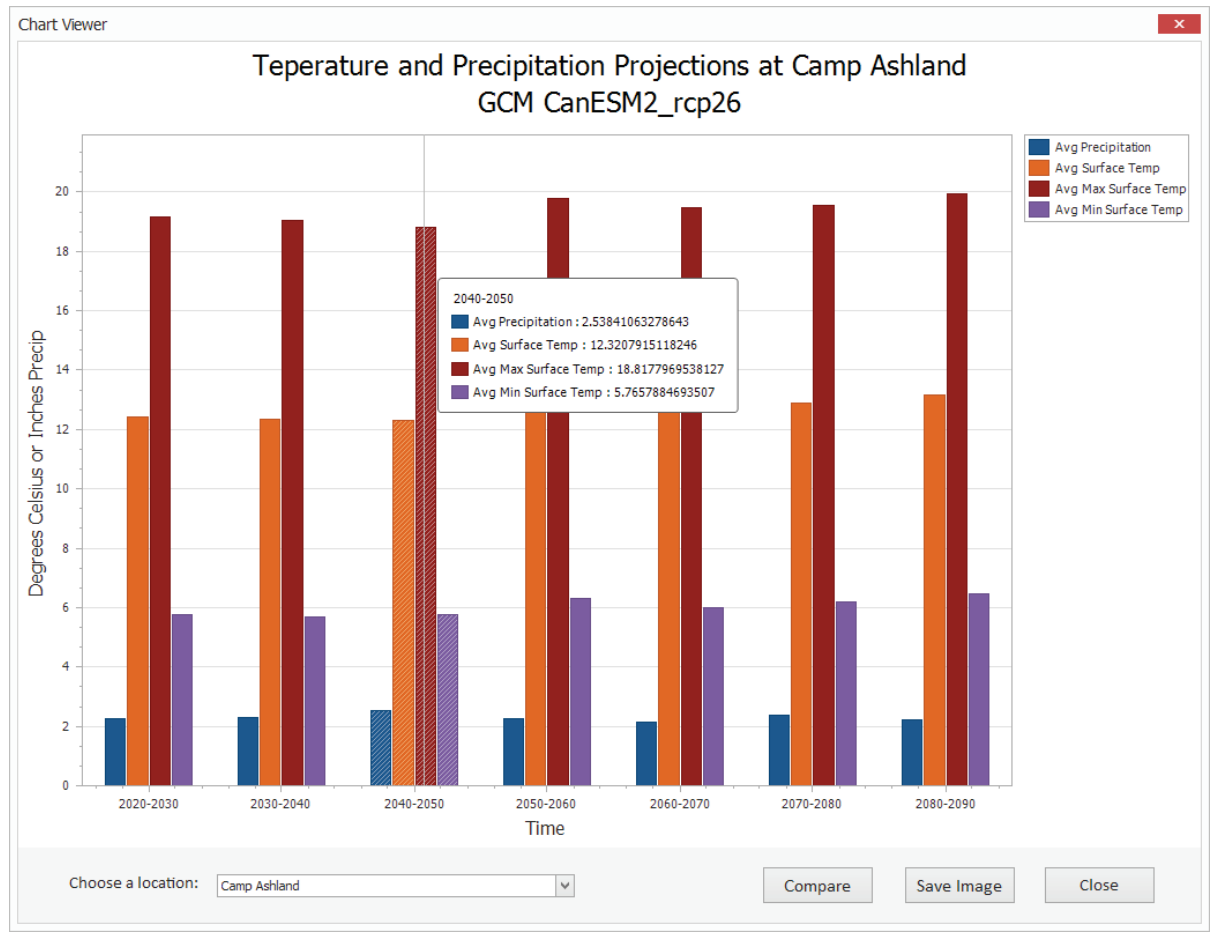

Average Precipitation, Surface Temp, Max Surface Temp, and Min Surface temp values are charted on the $\mathrm{Y}$-axis, and 10-year epochs are charted on the $\mathrm{X}$-axis (Figure 5). The user can change the charted values by choosing a different geographical location from the drop down combo box near the bottom left of the window. Upon selecting a location, the data will automatically filter to include only those values found within the chosen area.

Users may also limit the variables that are charted. Clicking the Compare button near the bottom right of the window brings up a dialog where variables may be shown or hidden from the chart (Figure 6).

Figure 6. Chart comparison filter.

\begin{tabular}{|c|c|c|}
\hline Choose & & $\mathbf{x}$ \\
\hline \multicolumn{3}{|c|}{$\checkmark$ Avg Precipitation } \\
\hline \multicolumn{2}{|c|}{$\checkmark$ Avg Surface Temperature } & \\
\hline \multicolumn{3}{|c|}{$\checkmark$ Avg Maximum Surface Temperature } \\
\hline \multicolumn{2}{|c|}{$\checkmark$ Avg Minimum Surface Temperature } & \\
\hline & OK & \\
\hline
\end{tabular}


Charts may be saved to the user's computer by clicking the Save Image button near the bottom right of the window (Figure 5). The resulting file is saved to a location of the user's choosing in the universal Joint Photographic Experts Group (JPEG) image file format. 


\section{Building New Data}

Building new datasets is accomplished within the VM by running an $\mathrm{R}$ Script from the R Studio development environment. The following instructions should be followed carefully to produce new data from this model.

The R Studio development environment is pre-installed inside the VM, and may be launched automatically from the Wizard application or accessed from the Windows Start menu (Figure 7 and Figure 8).

Figure 7. Launch R Studio from the third model screen within the Wizard.

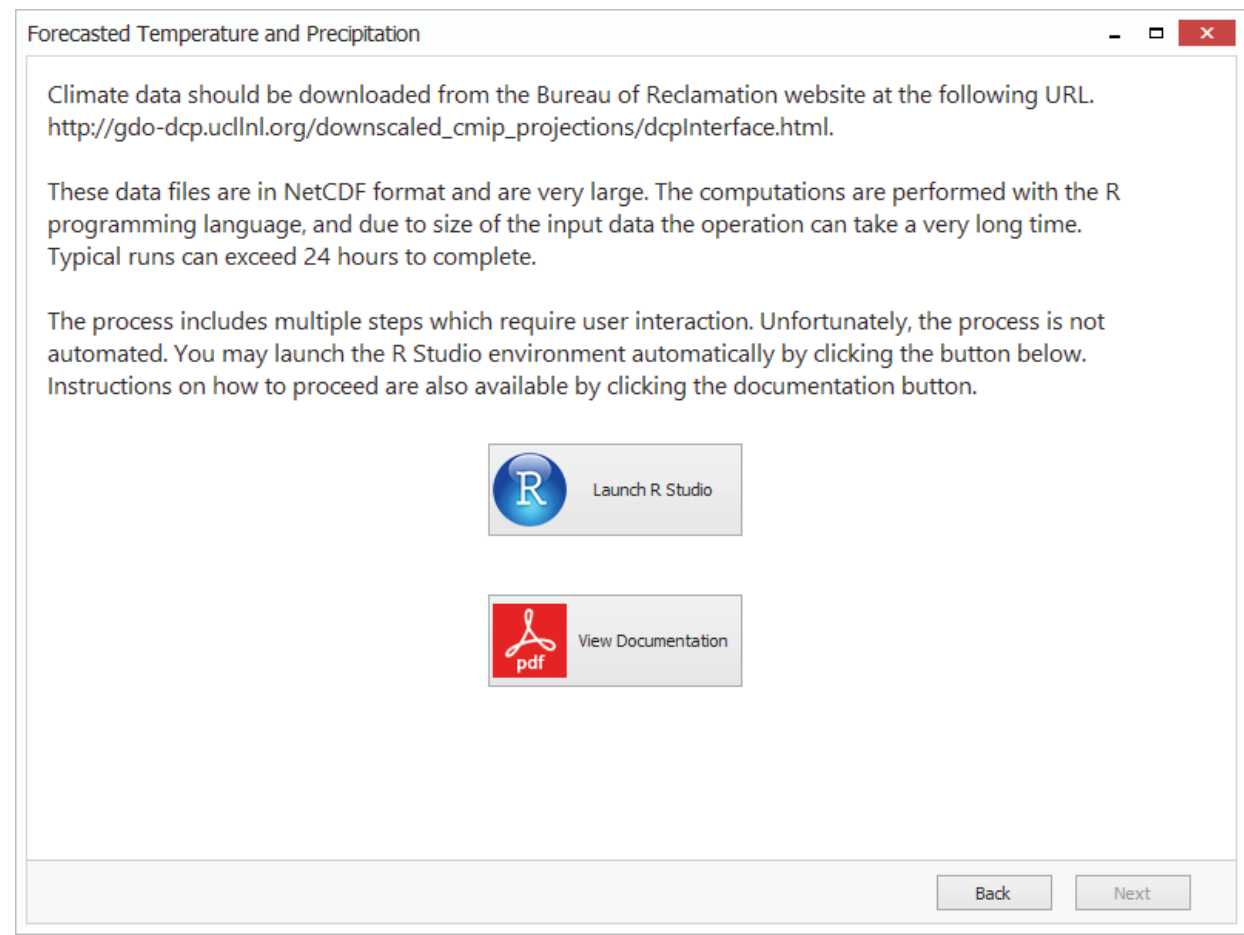


Figure 8. R Studio development environment

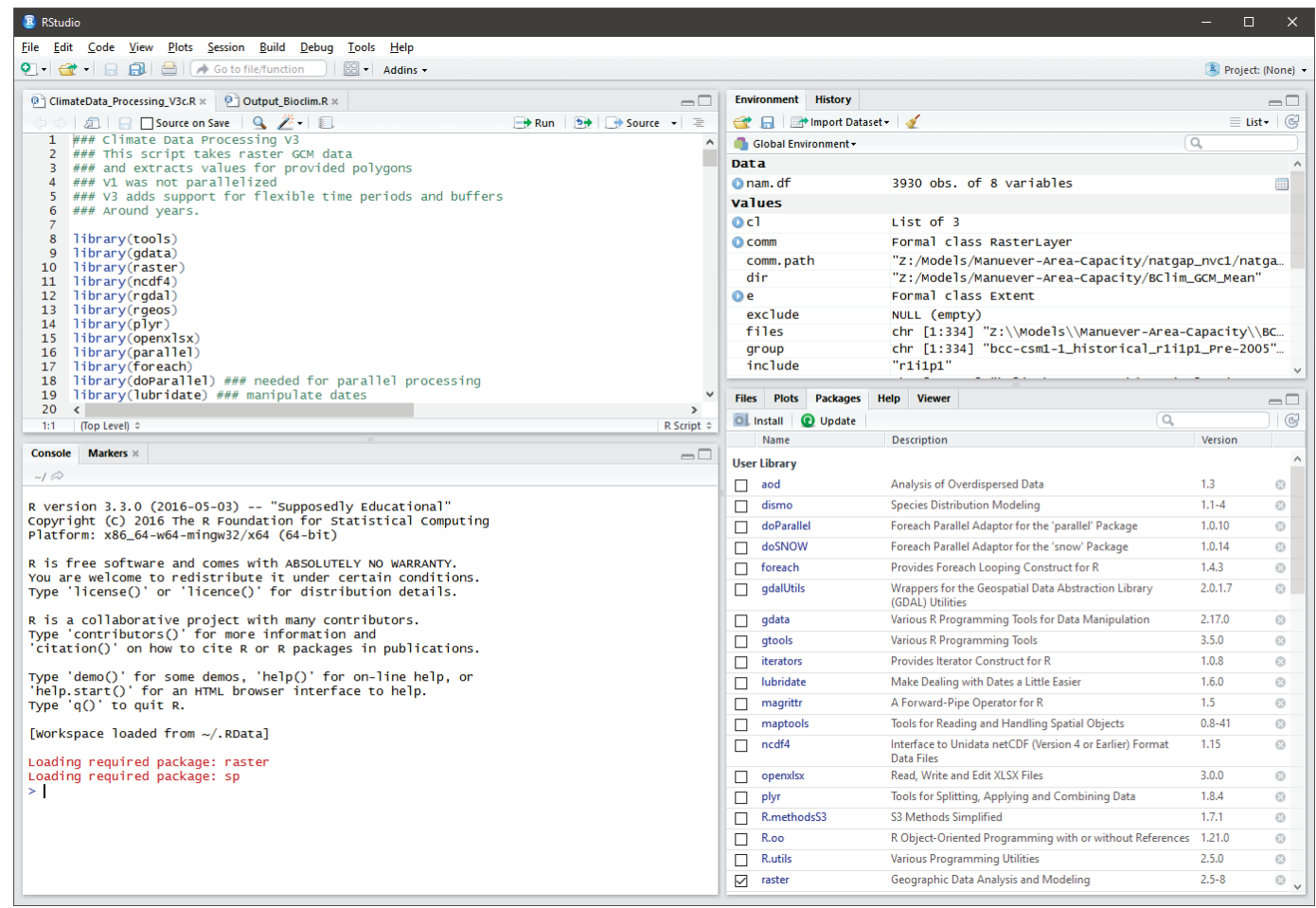

To run a script in R Studio, use the Code menu at the top. Choose Run Region-> Run All (Figure 9). 
Figure 9. Use the code menu to run a script.

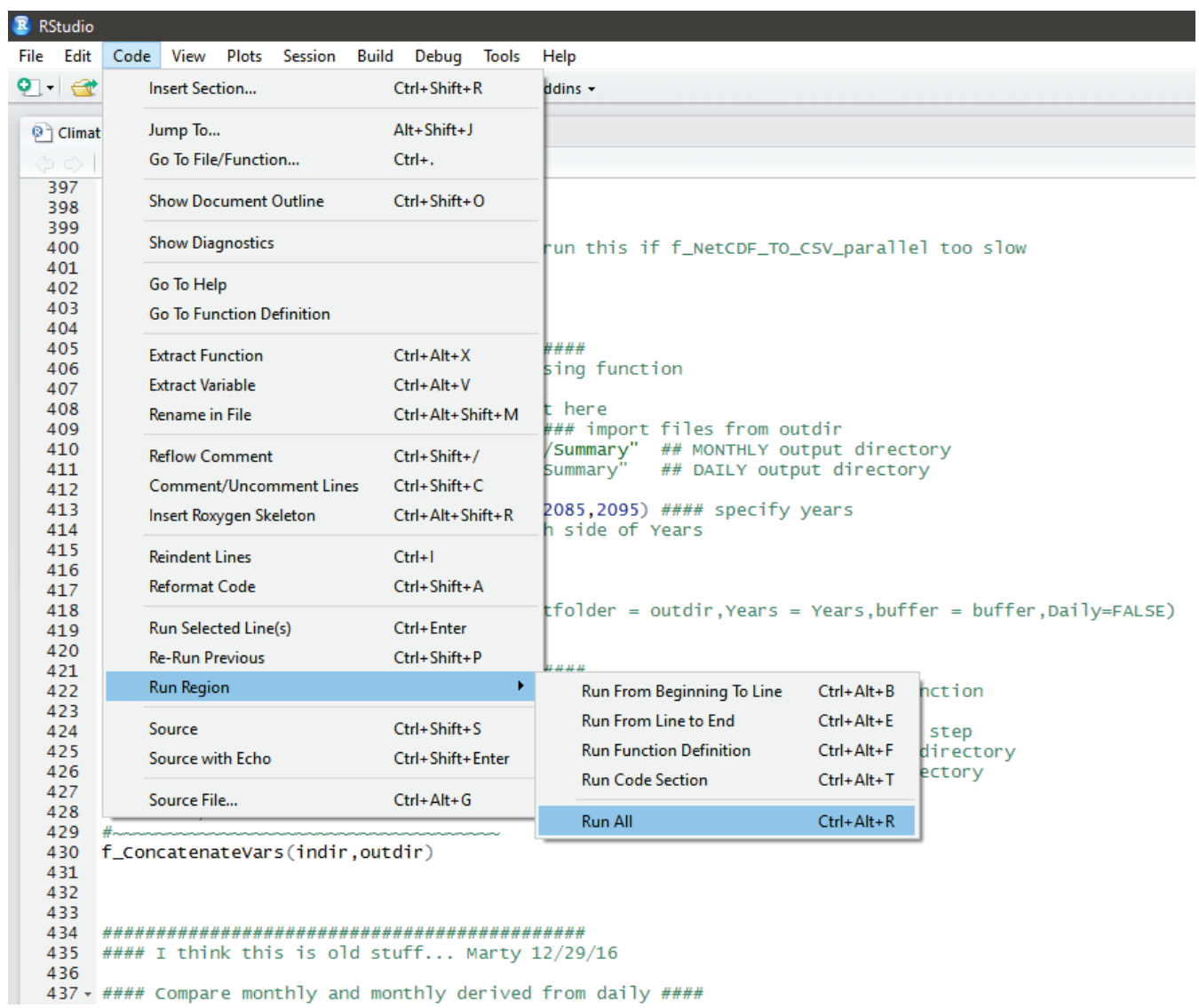

After opening R Studio, the appropriate R script should be loaded automatically. If it is not, open the R script by selecting File->open File and browse to the file C: \Models $\backslash$ Temp-PrecipProjections $\backslash$ Model $\backslash$ ClimateData_Processing_V3.R. Once the file is loaded, review the following lines to ensure the script performs the proper actions.

- Lines 72, 118, 217, 261. These lines are function declarations where the inputs to those functions are defined. The last function variable for each of them is daily. This variable must be set to either TRUE or FALSE depending on which type is desired. For example, "daily = TRUE" means daily values will be computed, and vice-versa.

- Lines 379-381. These lines define the input directories for the monthly and daily NetCDF files. BCSD indicates monthly data, and BCCA indicates daily data. Uncomment the appropriate line depending on the action required by removing the \# symbol and placing it in front of the previous action. 
- Line 383. Three RCPs were chosen to represent the upper, middle, and lower bounds. If additional RCPs are required, add them to the list.

- Lines 387-388. These lines define the output directories for the monthly and daily calculated results. Comment out the appropriate line using the same \# symbol method mentioned previously.

- Lines 396-400. These lines execute the functions that format the outputs in CSV format. Although all three can run at the same time, it is safer to run one at a time. That way errors can be caught without having to wait until all functions complete. Uncomment one line at a time by removing the \# symbol, execute the script, then replace the \# symbol and repeat for the other lines. Line 400 is a variant of function on line 399 and should not be used unless the function on line 399 fails.

- Lines 410-411. These lines define the output directory for the summarization function that formats the CSV output. Comment / uncomment them if processing daily or monthly values as described in previous steps, then uncomment line 418 and run the R script. Make sure to comment previous function calls on lines 396-400 to prevent running them again.

- Lines 425-426. These lines define the output directory for the concatenation function that further formats the CSV output. Comment/uncomment them if processing daily or monthly values as described in previous steps, then uncomment line 430 and run the $\mathrm{R}$ script. Make sure to comment previous function calls on lines 396-400 and line 418 to prevent running them again.

Output from this model is in the form of CSV files, one for each GCM/RCP combination. Note that this process can be rather lengthy, depending on the number of GCMs that are being processed. It is not unusual for the script to run for several hours.

After running the R script, another post processing script must be run. Locate the EXE file in the model folder within VM. (C: $\backslash$ Model $\backslash \mathrm{s} \backslash \mathrm{Temp}-$ Precip-Projections \Model \DataFixer.exe). Set the input and output paths by clicking the Change buttons. Ensure that the output folder that's entered exists before starting the process. Finally, click Fix It to process the data (Figure 10). 
Figure 10. Data Fixer tool.

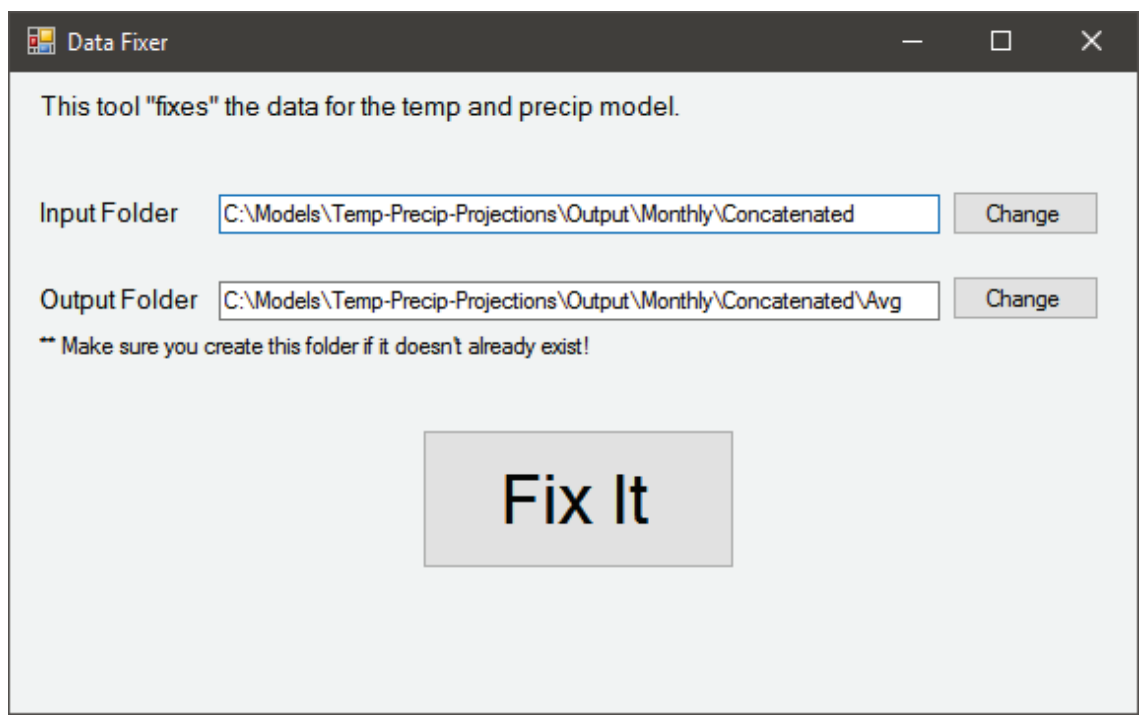

Post processing the data is fairly quick. It should not take more than a couple of minutes to complete. After this step, the data is ready to be viewed within the Wizard application. The post processing app source code is located at $\mathrm{C}: \backslash$ Models $\backslash$ VS Projects $\backslash$ DataFixerTempPrecip. 


\section{Known Issues and Limitations}

Building new data with this model can be a very lengthy process.

Depending on the number of GCMs being processed, it is not unusual for the R script to take several hours complete, even on very powerful, modern computers.

Significant hardware specifications are required to run this model. Typical desktop computers will not meet these requirements. A minimum of nine processor cores (eight required for script) are required to execute the code. Memory minimum requirements are 64GB of RAM and $5 \mathrm{~TB}$ of hard disk storage space (local or network). 


\section{Additional Help}

Additional questions or concerns should be directed to the Program Manager of the Integrated Climate Assessment for Army Enterprise Planning program.

Paul M. Loechl

ERDC-CERL

Paul.M.Loech|@usace.army.mil

217-373-5892

Marty Garton

ERDC-ITL

Byron.m.garton@usace.army.mil

601-634-2888 


\section{Reference}

Garton, B. M. 2019. Analytical Model Software Integration Methods. Special Report on Integrated Climate Assessment for Army Enterprise Planning. ERDC/ITL SR-194. Vicksburg, MS: Engineer Research and Development Center, Information Technology Laboratory (ERDC-ITL) 


\section{Appendix A: Acronyms and Abbreviations}

Term

AOGCMs

CMIP

CSV

DoD

ERDC

ERDC-CERL

ERDC-ITL

GB

GCM

JPEG

MVA

NetCDF

NSN

OMB

PM

RAM

RCP

\section{Definition}

Atmosphere-Ocean General Circulation Models

Coupled Model Intercomparison Project

Comma Separated Values

Department of Defense

Engineer Research and Development Center

Engineer Research and Development CenterConstruction Engineering Research Laboratory

Engineer Research and Development CenterInformation Technology Laboratory

Giga Bytes

Global Circulation Model

Joint Photographic Experts Group

Military Value Analysis

Network Common Data Format

National Supply Number

Office of Management and Budget

Program Manager

Random Access Memory

Representative Concentration Pathway 


$\begin{array}{ll}\text { SAR } & \text { Same As Report } \\ \text { SF } & \text { Standard Form } \\ \text { TB } & \text { Tera Bytes } \\ \text { VM } & \text { Virtual Machine } \\ \text { WCRP } & \text { World Climate Research Program } \\ \text { WGCM } & \text { Working Group on Coupled Modelling }\end{array}$




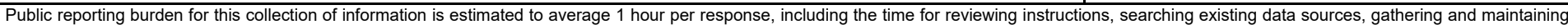

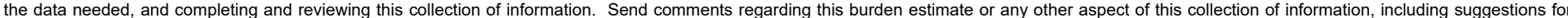

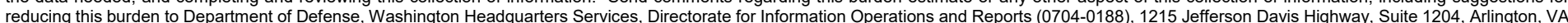

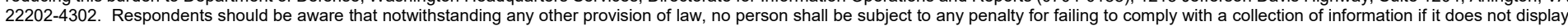
a currently valid OMB control number. PLEASE DO NOT RETURN YOUR FORM TO THE ABOVE ADDRESS.
1. REPORT DATE (DD-MM-YYYY)
2. REPORT TYPE
Final
July 2019

\section{TITLE AND SUBTITLE}

Temperature and Precipitation Projections Model User's Guide
3. DATES COVERED (From - To)

5a. CONTRACT NUMBER

5b. GRANT NUMBER

5c. PROGRAM ELEMENT NUMBER

\section{AUTHOR(S)}

Byron M. Garton

\section{5d. PROJECT NUMBER}

402188

5e. TASK NUMBER

5f. WORK UNIT NUMBER

8. PERFORMING ORGANIZATION REPORT NUMBER

ERDC/ITL SR-19-13

U.S. Army Engineer Research and Development Center

3909 Halls Ferry Road

Vicksburg, MS 39180

\section{SPONSORING / MONITORING AGENCY NAME(S) AND ADDRESS(ES)}

U.S. Army Corps of Engineers

Washington, DC 20314-1000

10. SPONSOR/MONITOR'S ACRONYM(S)

11. SPONSOR/MONITOR'S REPORT NUMBER(S)

\section{DISTRIBUTION / AVAILABILITY STATEMENT}

Approved for public release; distribution is unlimited

\section{SUPPLEMENTARY NOTES}

\section{ABSTRACT}

The potential effects of climate change on temperature and precipitation at Department of Defense (DoD) installations are far ranging, and understanding their impacts is essential to maintaining optimal force stationing and readiness. This model attempts to predict changes in daily and monthly average temperature and precipitation for several scenarios from future climate projections for various DoD installations.

This document describes the process of executing the Temperature and Precipitation Projections Model, as it exists at the time of this publication, within the common computational environment established under the software integration effort of the Integrated Climate Assessment for Army Enterprise Planning work package.

\section{SUBJECT TERMS}

Military bases

Meteorology

Temperature
Precipitation (Meteorology)

Climatic changes--Risk assessment

\section{SECURITY CLASSIFICATION OF:}

\section{a. REPORT}

Unclassified

\section{b. ABSTRACT}

Unclassified

\section{c. THIS PAGE}

Unclassified

\begin{tabular}{l|c|}
$\begin{array}{l}\text { 17. LIMITATION } \\
\text { OF ABSTRACT }\end{array}$ & $\begin{array}{c}\text { 18. NUMBER } \\
\text { OF PAGES }\end{array}$ \\
\cline { 2 - 2 } & 25
\end{tabular}

19a. NAME OF RESPONSIBLE PERSON

19b. TELEPHONE NUMBER (include area code) 